\title{
Adsorptive removal of heavy metals by magnetic nanoadsorbent: an equilibrium and thermodynamic study
}

\author{
D. S. Shirsath • V. S. Shirivastava
}

Received: 19 November 2014 / Accepted: 8 December 2014/Published online: 7 January 2015

(C) The Author(s) 2015. This article is published with open access at Springerlink.com

\begin{abstract}
An efficient and new magnetic nanoadsorbent photocatalyst was fabricated by co-precipitation technique. This research focuses on understanding metal removal process and developing a cost-effective technology for treatment of heavy metal-contaminated industrial wastewater. In this investigation, magnetic nanoadsorbent has been employed for the removal of $\mathrm{Zn}$ (II) ions from aqueous solutions by a batch adsorption technique. The adsorption equilibrium data fitted very well to Langmuir and Freundlich adsorption isotherm models. The thermodynamics of $\mathrm{Zn}(\mathrm{II})$ ions adsorption onto the magnetic nanoadsorbents indicated that the adsorption was spontaneous, endothermic and physical in nature. Surface morphology of magnetic nanoadsorbent by scanning electron microscopy (SEM) and elemental analysis by EDX technique. The structural and photocatalytic properties of magnetic nanoadsorbent were characterized using X-ray diffraction (XRD) and FTIR techniques. Also, the magnetic properties of synthesized magnetic nanoadsorbent were determined by vibrating spinning magnetometer (VSM).
\end{abstract}

Keywords Magnetic nanoadsorbent - Batch adsorption · Heavy metals · Adsorption isotherm · Endothermic

D. S. Shirsath · V. S. Shirivastava $(\bowtie)$

Nanochemistry Research Laboratory, G.T.Patil College,

Nandurbar 425412, MS, India

e-mail: drvinod_shrivastava@yahoo.com

D. S. Shirsath

e-mail: dhanrajshirsath111@gmail.com

\section{Introduction}

Nanotechnology has been considered as one of the most important advancements in science and technology. Its essence is the ability to fabricate and engineer the materials and systems with the desired structures and functionalities using the nanosized building blocks (Siegel et al. 1999). Nanoparticles are one of the important building blocks in fabrication of nanomaterials. Their basic properties, extremely small size and high surface area to volume ratio, provide better kinetics for the adsorption of metal ions from aqueous solutions. However, for such an application, it is necessary to use a method of purification that does not generate secondary waste and involves materials that can be recycled and easily used on an industrial scale (Ngomsik et al. 2005).

In most industrial countries, heavy polluters like metallurgy industries have been forced to improve their techniques and to radically reduce the discharge of toxic trace metals to the atmosphere and water. Over the same period, the production, transformation and use of these metals in society, sometimes referred to as metal metabolism, have increased (Bergbäck 1992).

The most severe medical and ecological effects have been observed in areas with intense mining and metallurgy industries. During processing of the ore, the toxic metals, which often naturally occur at very low concentrations (trace metals), are released to the environment, resulting in high concentrations at a local scale. As a consequence, until the 1980s such metal pollution was generally considered to be a local problem mainly occurring around an easily identified point source. However, even on a global scale, anthropogenic activities are the most important source of the potentially toxic metals found in the environment (Campbell et al. 1983). Around 
15 times more cadmium $(\mathrm{Cd}), 100$ times more lead $(\mathrm{Pb})$, 13 times more copper $(\mathrm{Cu})$ and 21 times more zinc $(\mathrm{Zn})$ are emitted to the atmosphere by human activities than by natural processes (Ross 1994). Therefore, for the removal of heavy metal, activated carbon has undoubtedly been the most popular and widely used adsorbent in wastewater treatment applications throughout the world. In spite of its prolific use, activated carbon remains an expensive material since higher the quality of activated carbon, the greater its cost. Activated carbon also requires complexing agents to improve its removal performance for inorganic matters.

Therefore, this situation makes it no longer attractive to be widely used in small-scale industries because of cost inefficiency. Due to the problems mentioned previously, research interest into the production of alternative adsorbents to replace the costly activated carbon has intensified in recent years. Attention has been focused on the various adsorbents, which have metal-binding capacities and are able to remove unwanted heavy metals from contaminated water at low cost.

With the rapid development of nanotechnology, magnetic nanoparticles are currently studied widely. Superparamagnetic iron oxide $\left(\mathrm{Fe}_{3} \mathrm{O}_{4}\right)$ nanoparticles have attracted researchers from various fields such as physics, medicine, biology, and materials science due to their multifunctional properties such as small size, superparamagnetism, and low toxicity ( $\mathrm{Gu}$ et al. 2006; Katz and Willner 2003). Several methods have been developed to synthesize magnetic $\mathrm{Fe}_{3} \mathrm{O}_{4}$ nanoparticles: (1) co-precipitation of ferrous $\left(\mathrm{Fe}^{2+}\right)$ and ferric $\left(\mathrm{Fe}^{3+}\right)$ aqueous solution in the presence of a base (Kang et al. 1996); (2) thermal decomposition of an iron complex (Woo et al. 2004); (3) by a sonochemical approach (Suslick et al. 1996). However, $\mathrm{Fe}_{3} \mathrm{O}_{4}$ nanoparticles tend to aggregate due to strong magnetic dipole-dipole attractions between particles. So, stabilizers such as surfactants, oxide or polymeric compounds (especially biocompatible polymer) with some specific functional groups have been used to modify these particles to increase the stability (Santra et al. 2001; Mikhaylova et al. 2004; Wa et al. 2006; Kim et al. 2006).

The difficulty in preparing $\mathrm{Fe}_{3} \mathrm{O}_{4}$ magnetic nanoparticles by chemical co-precipitation is the tendency of agglomeration of particles because of extremely small particle size leading to great specific surface area and high surface energy, consideration of effect of alkali, emulsifier, and reaction temperature are the decisions making factors of final product (Zhao et al. 2008).

In present study, the methods such as high-temperature decomposition of organic precursors, microemulsions, polyols, other solution techniques are require high temperature, sophisticated instruments, high-cost precursor compounds and time consuming. Therefore, $\mathrm{Fe}_{3} \mathrm{O}_{4}$ magnetic nanoparticles synthesized by co-precipitation method. The co-precipitation method is simple and gives effective result within $15 \mathrm{~min}$. Also, no sophisticated instrumentation and assembly required for synthesis of $\mathrm{Fe}_{3} \mathrm{O}_{4}$ nanoparticles. The chemical co-precipitation reaction is ecofriendly and cost effective because only two iron precursors and dilute solution of $\mathrm{NH}_{4} \mathrm{OH}$ were required in present research article. During the fabrication of $\mathrm{Fe}_{3} \mathrm{O}_{4}$ nanoparticles there is no harmful by-product formation takes place, very small amount of heat energy required for the rise in temperature up to $70{ }^{\circ} \mathrm{C}$, therefore, it is an energy-efficient reaction.

The synthesized $\mathrm{Fe}_{3} \mathrm{O}_{4}$ employed for the treatment of aqueous solution of $\mathrm{Zn}$ (II) ions. These treatability studies focus on the synthesis of $\mathrm{Fe}_{3} \mathrm{O}_{4}$ nanoparticles and their application in effective removal of $\mathrm{Zn}$ (II) ions from industrial and sewage wastewater by batch adsorption process. Different parametric studies were also carried out for determining optimum factors of corresponding parameters; the optimum $\mathrm{pH}$ is 5.5. This new technique developed is beneficial to water treatment and water purification processes.

\section{Experimental}

\section{Materials and methods}

Stock metal solutions were prepared by dissolving stoichiometric amount of $\mathrm{Zn}\left(\mathrm{NO}_{3}\right)_{2}$ in double-distilled water (DDW). All the reagents were used are A.R grade and obtained from Loba Chemie Industries Ltd. Mumbai.

\section{Batch adsorption experiments}

The experiments were conducted by introducing $60 \mathrm{mg}$ $\left(2 \mathrm{~g} \mathrm{~L}^{-1}\right)$ of magnetic nanoadsorbent into a series of conical flasks $100 \mathrm{ml}$ containing $30 \mathrm{~mL}$ of solutions having a metal concentration of $10 \mathrm{mg} \mathrm{L}^{-1}$. The glass conical flasks containing reaction mixture were agitated on magnetic stirrer at $25{ }^{\circ} \mathrm{C}$ for $1.30 \mathrm{~h}$. The adsorbent treated colloidal solution was separated from the metal solution by centrifugation at 3,000 rpm for $20 \mathrm{~min}$. The concentration of the metal in the remaining solution (supernatant liquid) was measured by double-beam spectrophotometer at systronics2203.

$\mathrm{Fe}_{3} \mathrm{O}_{4}$ nanoparticles were prepared by co-precipitation method with a ferrous complex in presence of $\mathrm{NH}_{4} \mathrm{OH}$. First, $\mathrm{FeCl}_{2} \cdot 4 \mathrm{H}_{2} \mathrm{O}$ and $\mathrm{FeCl}_{3} \cdot 6 \mathrm{H}_{2} \mathrm{O}\left[\mathrm{Fe}^{2+}: \mathrm{Fe}^{3+}=1: 2\right]$ were dissolved in about $50 \mathrm{ml}$ de-ionized water, and stirring this solution under strong ultrasonic agitation while heating solution to $70{ }^{\circ} \mathrm{C}$. Next, this iron solution source 
was added dropwise into $\mathrm{NH}_{4} \mathrm{OH}$ under strong ultrasonic agitation for $30 \mathrm{~min}$, and bubbling $\mathrm{N}_{2}$ gas.

The chemical reaction of $\mathrm{Fe}_{3} \mathrm{O}_{4}$ precipitation is expected as follows:

$$
\begin{aligned}
& \mathrm{FeCl}_{2} \cdot 4 \mathrm{H}_{2} \mathrm{O}+2 \mathrm{FeCl}_{3} \cdot 6 \mathrm{H}_{2} \mathrm{O}+8 \mathrm{NaOH} \\
& \quad \rightarrow \mathrm{Fe}_{3} \mathrm{O}_{4}+8 \mathrm{NaCl}+20 \mathrm{H}_{2} \mathrm{O}
\end{aligned}
$$

Black $\mathrm{Fe}_{3} \mathrm{O}_{4}$ particles were decanted by permanent magnet and cleaned by de-ionized water several times.

The magnetic properties of $\mathrm{Fe}_{3} \mathrm{O}_{4}$ nanoparticles can be observed visually. Photo image shows the iron oxide $\mathrm{Fe}_{3} \mathrm{O}_{4}$ nanoparticles in a vial as a magnet is brought in contact with the side of the vial. The $\mathrm{Fe}_{3} \mathrm{O}_{4}$ nanoparticles are attracted to the wall of the vial by the magnetic field.

This experimental study influences that these magnetic nanoparticles will be easily removed from aqueous solution after use by a permanent magnet as shown in the following photo image.

\section{Result and discussion}

The influences of various parameters have been discussed below. These parameters have been studied in the literature for different other adsorbent and contaminants but the results obtained and presented for magnetic nanoadsorbent in intact and pre-treated forms used for treating aqueous solutions containing $\mathrm{Zn}$ (II) ion different concentrations are presented here for treatment of industrial wastewater containing heavy metals.

\section{Effect of $\mathrm{pH}$}

Experiments were conducted with intact and modified magnetic nanoadsorbent for $\mathrm{Zn}$ (II) adsorption in batch systems. The adsorption characteristic of metal adsorption at various $\mathrm{pH}$ values in the range was examined. Although all the experiments have been carried out for all intact and pre-treated magnetic nanoadsorbent, for this reason only the optimum modifier has been plotted. As shown in Fig. 1, the adsorption of $\mathrm{Zn}$ (II) metals ion is highly $\mathrm{pH}$ dependent and adsorption of Zinc is highest at $\mathrm{pH}$ values of 5.5 and then decreases as the $\mathrm{pH}$ increases.

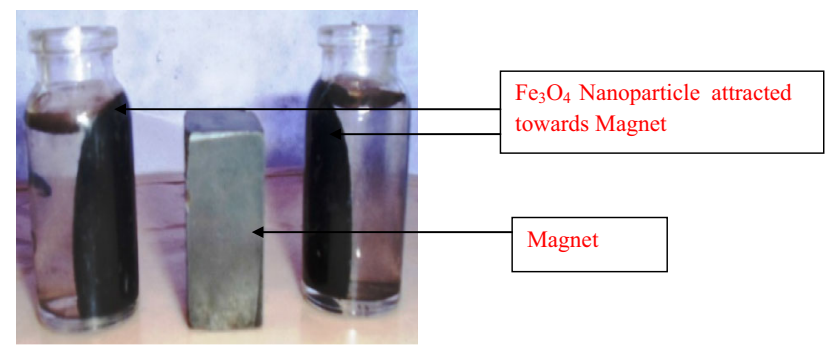

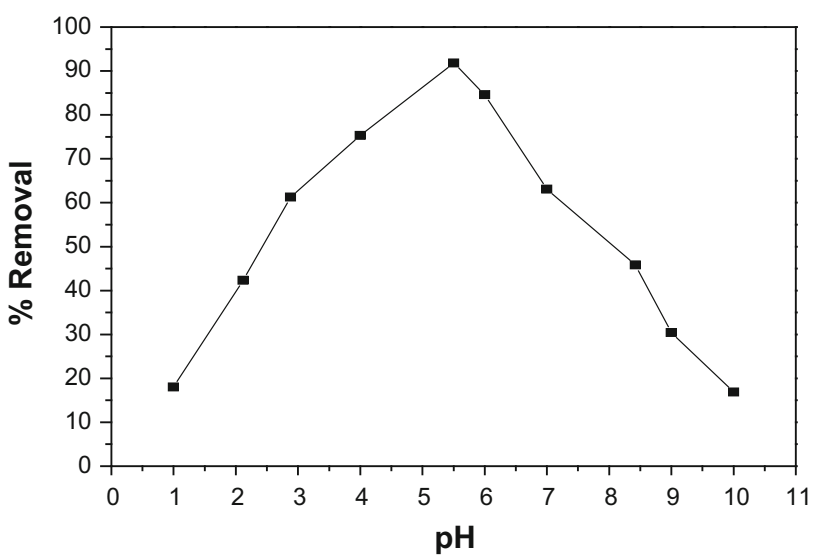

Fig. 1 Effect of $\mathrm{pH}$ on $\mathrm{Zn}(\mathrm{II})$ ions removal

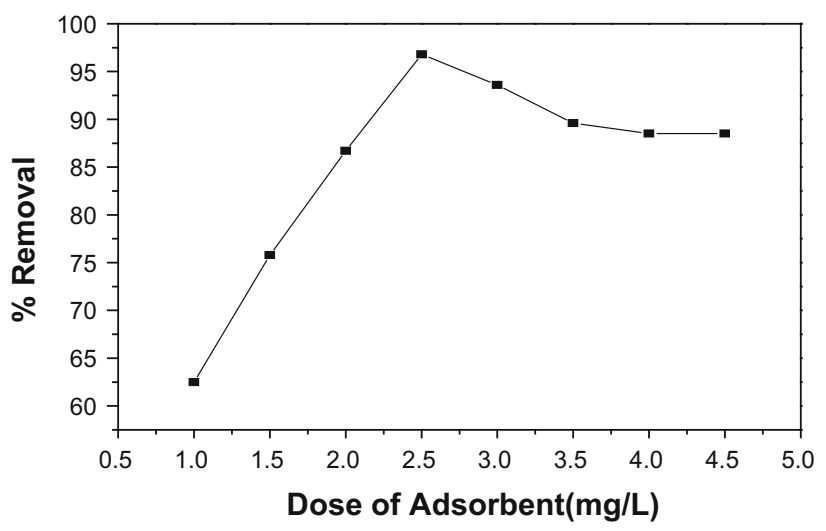

Fig. 2 Effect of adsorbent dose on Zn(II) ions removal

Effect of adsorbent dose

Magnetic nanoadsorbent has a great influence on the adsorption process and determines the potential of removal of $\mathrm{Zn}$ (II) ions through the number of binding sites available to remove metal ions at a specified metal initial concentration. The effect of Magnetic nanoadsorbent on $\mathrm{Zn}$ (II) ion removal is indicated in Fig. 2. At equilibrium, capacity of $\mathrm{Zn}$ (II) ion removal decreases with an increase in magnetic nanoadsorbent dosage from 0.5 to $5 \mathrm{mg}$. This decrease can be due to the concentration gradient.

Effect of contact time

As the adsorption process proceeds, the sorbent reaches the saturation state and then the sorbed solute tends to desorb back into the solution. Eventually, the rates of adsorption and desorption will be equal at equilibrium. When the system reaches sorption equilibrium, no further net adsorption occurs. The time at which adsorption equilibrium occurs was determined (Sari and Tuzen 2008). In 


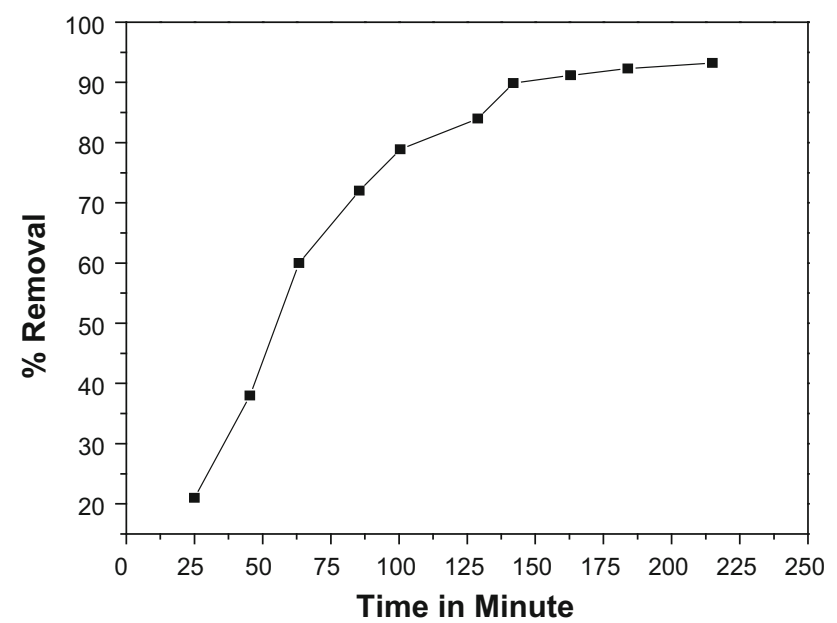

Fig. 3 Effect of contact time on $\mathrm{Zn}$ (II) ions removal

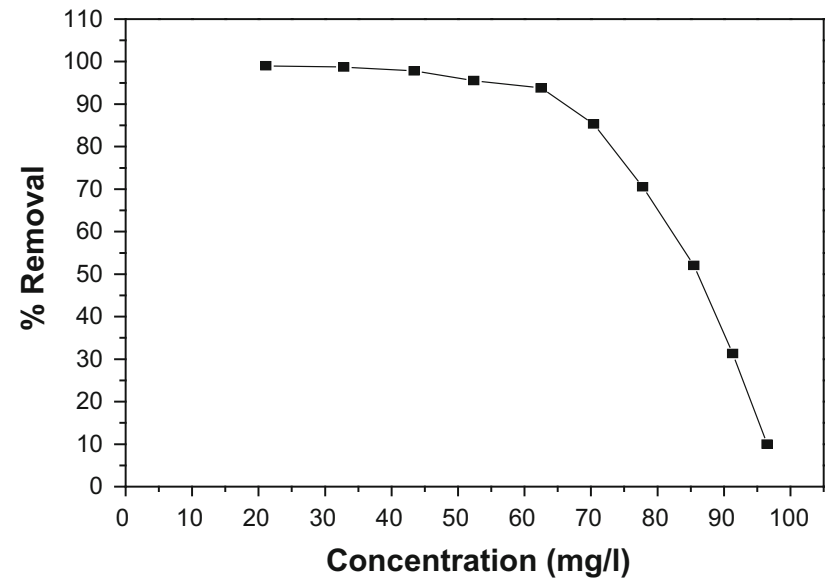

Fig. 4 Effect of initial concentration of $\mathrm{Zn}(\mathrm{II})$ ions

industry, this time is very important for the process optimization. The adsorption rate tests were performed on an equilibrium batch basis. The adsorbent was kept in contact with the metal-bearing solution for different times $(25,50$, $75 \mathrm{~min}, 1,2,4,8$ and $16 \mathrm{~h}$ ). From the experimental data represented in Fig. 3, the process of adsorption reaches the equilibrium state after approximately $2.5 \mathrm{~h}$ of contact. The reaction rate is rather fast at first and $80 \%$ of total removal of $\mathrm{Zn}$ (II) ions of metals occurs in the first $55 \mathrm{~min}$ and thereafter it proceeds at a lower rate and finally no further significant adsorption is noted beyond $1.5 \mathrm{~h}$. The very fast sorption and settling of the contact time make this material suitable for continuous flow water treatment systems.

\section{Effect of initial metal concentration}

The adsorption of $\mathrm{Zn}$ (II) ions was tested at lower concentrations because of their hazardous and toxic effect. Figure 4 indicates that the metal sorption capacity increases with an increase in the initial metal ion concentration. This is due to an increase in the initial ion concentration providing a larger driving force to overcome all mass transfer resistances between the solid and the aqueous phase, thus resulting in higher metal ion adsorption at initial stages. As concentration of $\mathrm{Zn}$ (II) ions in solution increases there is no further adsorption because of blocking of surface area of adsorbent. Similar results have been reported (Sari and Tuzen 2010; Riaz et al. 2009; Nasuha et al. 2010).

\section{Result and discussion}

\section{SEM analysis}

The scanning electron microscopy (SEM) analysis shows the morphological structure of the material. In this result, there is distinct adsorption of $\mathrm{Zn}$ (II) ions on magnetic nanoadsorbent as Figs. 5a, 6a before adsorption show fine highly uniform nanosized surface area and Figs. 5b, 6b show change in uniform structure after adsorption of $\mathrm{Zn}$ (II) ions on $\mathrm{Fe}_{3} \mathrm{O}_{4}$ iron oxide nanoparticles. Adsorbed particles such as $\mathrm{Zn}$ (II) ions as well as the iron oxide particles are seen after adsorption. The iron oxide $\mathrm{Fe}_{3} \mathrm{O}_{4}$ nanoparticles exhibit magnetic behavior, creating more negative charges. The positively charged $\mathrm{Zn}$ (II) ions will be electrostatically attracted to the $\mathrm{Fe}_{3} \mathrm{O}_{4}$ nanoparticles. This is depicted by more particles being adsorbed in Figs. 5b, 6b. The nanosized structure of adsorbent has large surface area, which shows sufficient removal of $\mathrm{Zn}$ (II) ions from the aqueous solution.

\section{XRD analysis}

X-ray diffraction analysis of material gives the information of planes and size of synthesized material. In this study, magnetic nanoadsorbent shows the $2 \theta$ adsorption peaks in Fig. 7 at $30.2^{\circ}, 35.5^{\circ}, 42.8^{\circ}, 52.8^{\circ}, 57.6^{\circ}, 62.8^{\circ}$, representing corresponding planes at 220, 311, 400, 422, 551 and 440, respectively. This clearly indicates that synthesized material Iron oxide magnetic nanoadsorbent is nanosized by calculating using Scherer formula Eq. (1). The data revealed that the magnetic nanoadsorbent is pure $\mathrm{Fe}_{3} \mathrm{O}_{4}$. The nanoadsorbent has large surface area, their unique size-dependent properties make these nanomaterials superior and indispensable in many areas of human activities such as medicine, environment, electronic, automotives, cosmetics. Here, magnetic nanomaterial holds the promise for producing better with less input energy or materials. Also, other application is developing specific drug delivery system and lab on a chip-based diagnostic for a minimal invasive medicine, improving information and communication through smaller and more powerful electronic devices. 

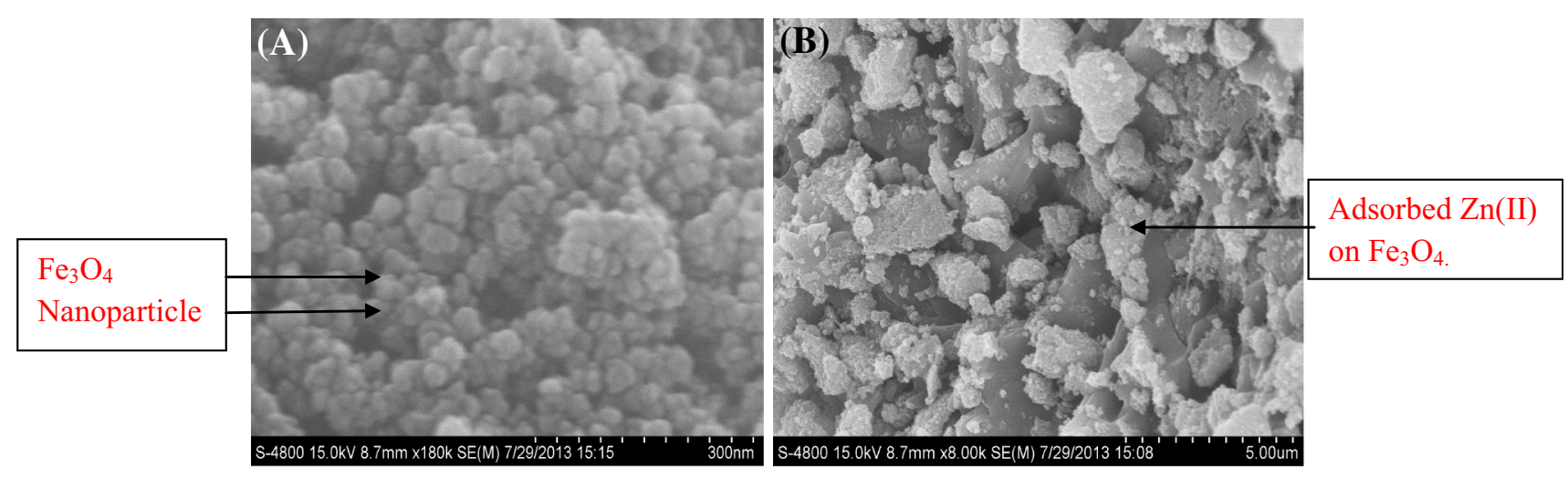

Fig. 5 a Before adsorption, b after adsorption

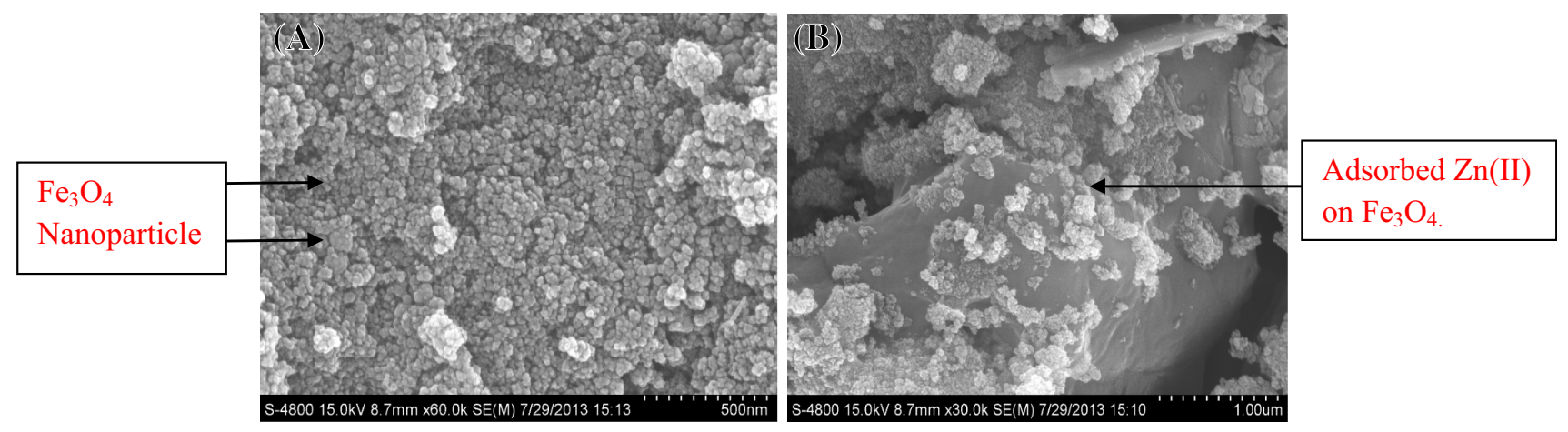

Fig. 6 a Before adsorption, b after adsorption

Fig. 7 XRD pattern of magnetic nanoadsorbent

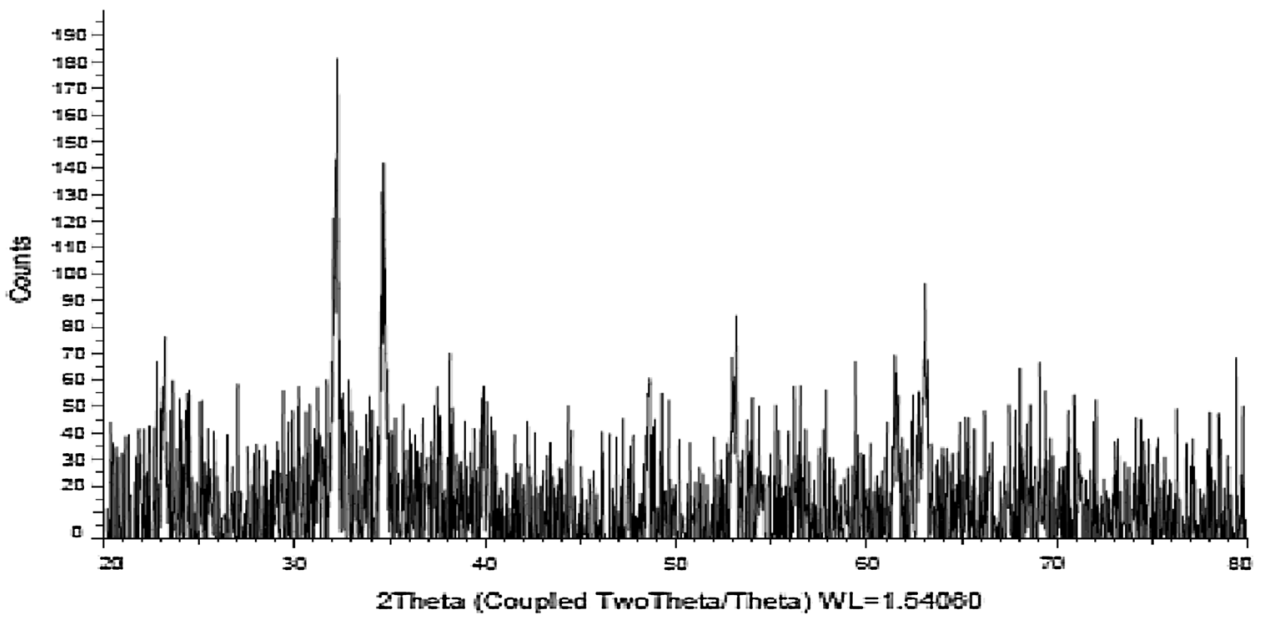

indicates that magnetic nanoadsorbent was useful for the removal of $\mathrm{Zn}$ (II) ions from aqueous solution.

\section{FTIR analysis}

The FTIR spectrum of synthesized magnetic material is of iron oxide magnetic nanoadsorbent. Figure 9 shows blue shift and characteristic absorption bands at $589 \mathrm{~cm}^{-1}$ of the the synthesized material contains $61 \%$ of oxygen, $37 \%$ of iron and $2 \%$ zinc as shown in Table 1 . This clearly

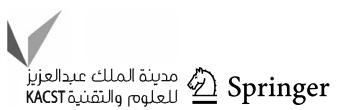


Fig. 8 The EDS spectra of magnetic nanoadsorbent treated with $\mathrm{Zn}$ (II) ion solution

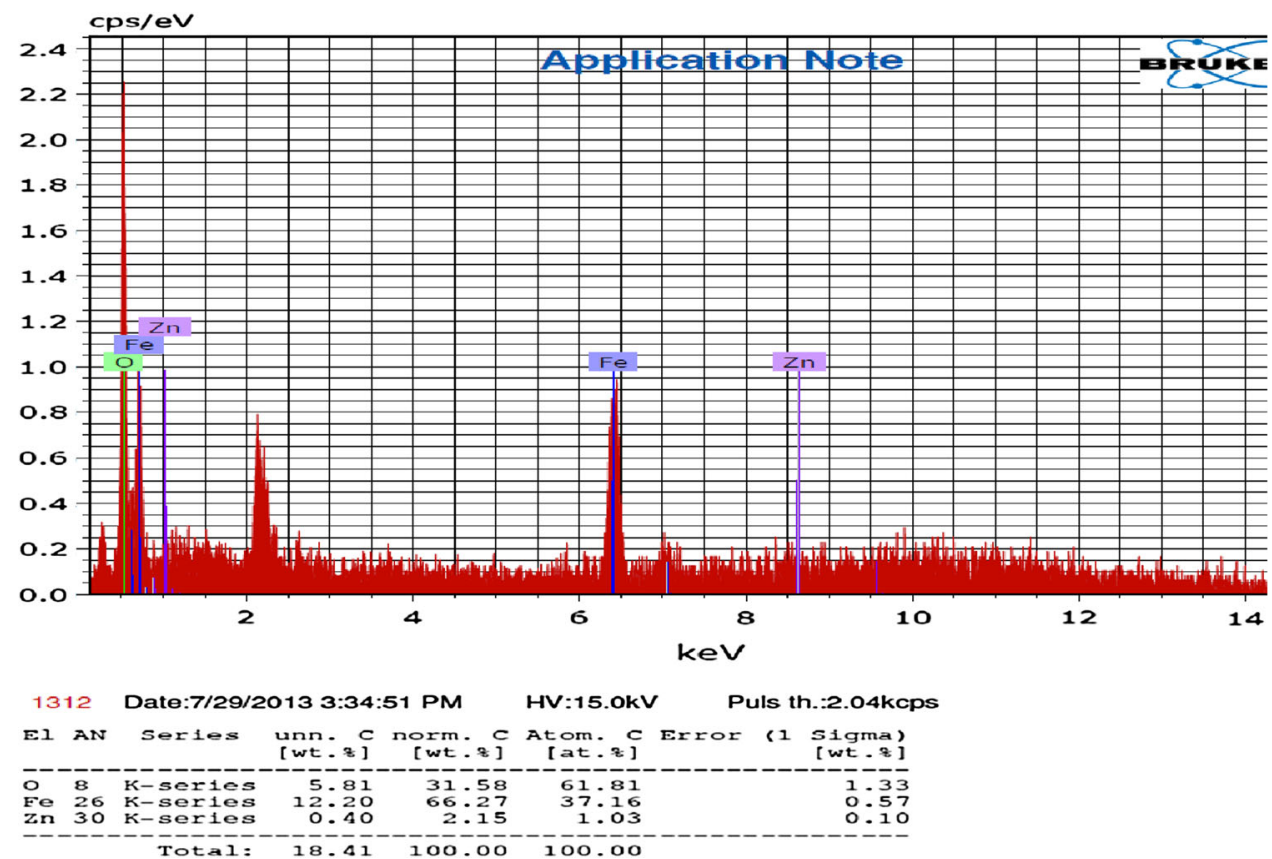

Table 1 Percentage of elements and its elementary weight in synthesized magnetic nanoadsorbent

\begin{tabular}{ll}
\hline Elements & Elementary weight $(\%)$ \\
\hline $\mathrm{Fe}$ & 61 \\
$\mathrm{O}$ & 37 \\
$\mathrm{Zn}$ & 1 \\
\hline
\end{tabular}

$\mathrm{Fe}-\mathrm{O}$ bond. Previously, it was reported that the characteristic absorption band of $\mathrm{Fe}-\mathrm{O}$ bond of bulk $\mathrm{Fe}_{3} \mathrm{O}_{4}$ was at 599 and $375 \mathrm{~cm}^{-1}$ (Waldron 1995). However, when the size of $\mathrm{Fe}_{3} \mathrm{O}_{4}$ particles was reduced to nanoscale dimensions, the surface bond force constant increased due to the effect of finite size of nanoparticles, in which the breaking of large number of bonds for surface atoms resulted in the rearrangement of non-localized electrons on the particle surface (Ma et al. 2003).

\section{VSM analysis}

The most common measurement method employed for hysteresis loop determinations at ambient temperature is the vibrating sample magnetometer (VSM). This system is used to measure the magnetic properties of materials as a function of magnetic field, temperature, and time. Also, VSM analysis gives the idea about whether the magnetization is parallel or perpendicular to the plane defined by the substrate. In present result, VSM characterization carried out at 0-10,000 gauss and observed magnetization (Ms) about 59 emu $\mathrm{gm}^{-1}$ in $\mathrm{Fe}_{3} \mathrm{O}_{4}$ nanoparticles. Based on
Fig. 10, VSM curve at room temperatures and magnetic behavior of the magnetic nanoadsorbent can be identified. For example, at room temperature, $\mathrm{Fe}_{3} \mathrm{O}_{4}$ particles show hysteresis loop feature, indicating that the magnetic $\mathrm{Fe}_{3} \mathrm{O}_{4}$ particles are paramagnetic; from this, it is clear that the magnetic moment aligns perpendicular to the applied magnetic field $(\mathrm{H})$. Magnetic properties of the $\mathrm{Fe}_{3} \mathrm{O}_{4}$ particles depend upon crystalline nature of the nanoparticles. We can optimize the magnetic property by increasing crystallinity of the $\mathrm{Fe}_{3} \mathrm{O}_{4}$ nanoparticles. Also, from the plateau part of the VSM curve, saturation magnetization (Ms) can be determined. In present characterization, most important is that the $\mathrm{Fe}_{3} \mathrm{O}_{4}$ particles materials should possess sufficient magnetic properties for use in practical applications and it is very useful in the present study.

\section{Kinetic study}

Kinetic study provides valuable information about the mechanism of adsorption and subsequently investigation of the controlling mechanism of the adsorption process as either mass transfer or chemical reaction to obtain the optimum operating conditions for industrial-scale batch processes (Alyuz and Veli 2009). In batch systems, adsorption kinetics is described by a number of models based on adsorption equilibrium such as the pseudo-firstorder and the pseudo-second-order kinetic models. The linearized pseudo-first-order kinetic model takes the following form of Eq. (2) (Chen et al. 2008; Basha and Murthy 2007). 


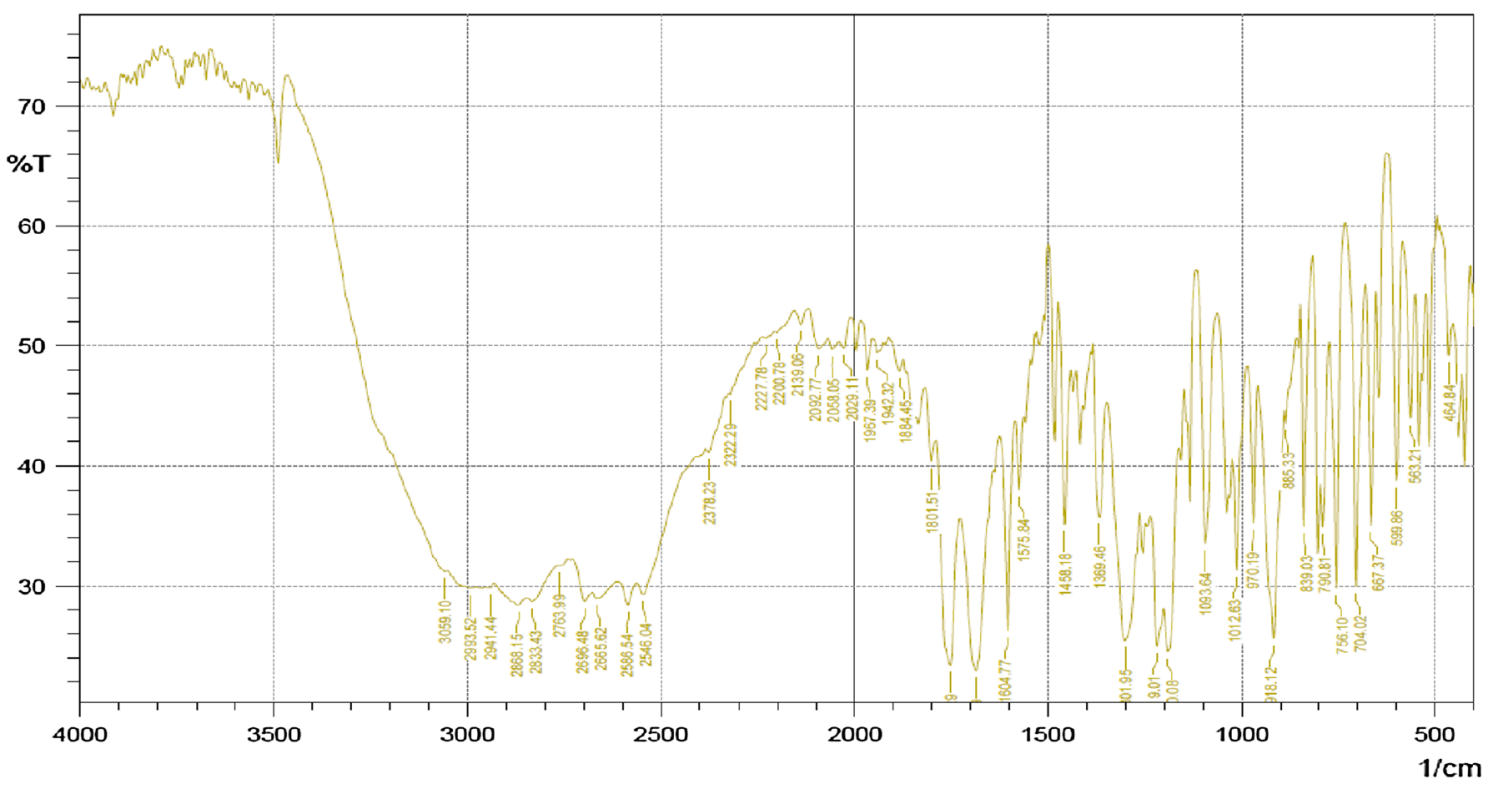

Fig. 9 FTIR spectrum of synthesized magnetic nanoadsorbent

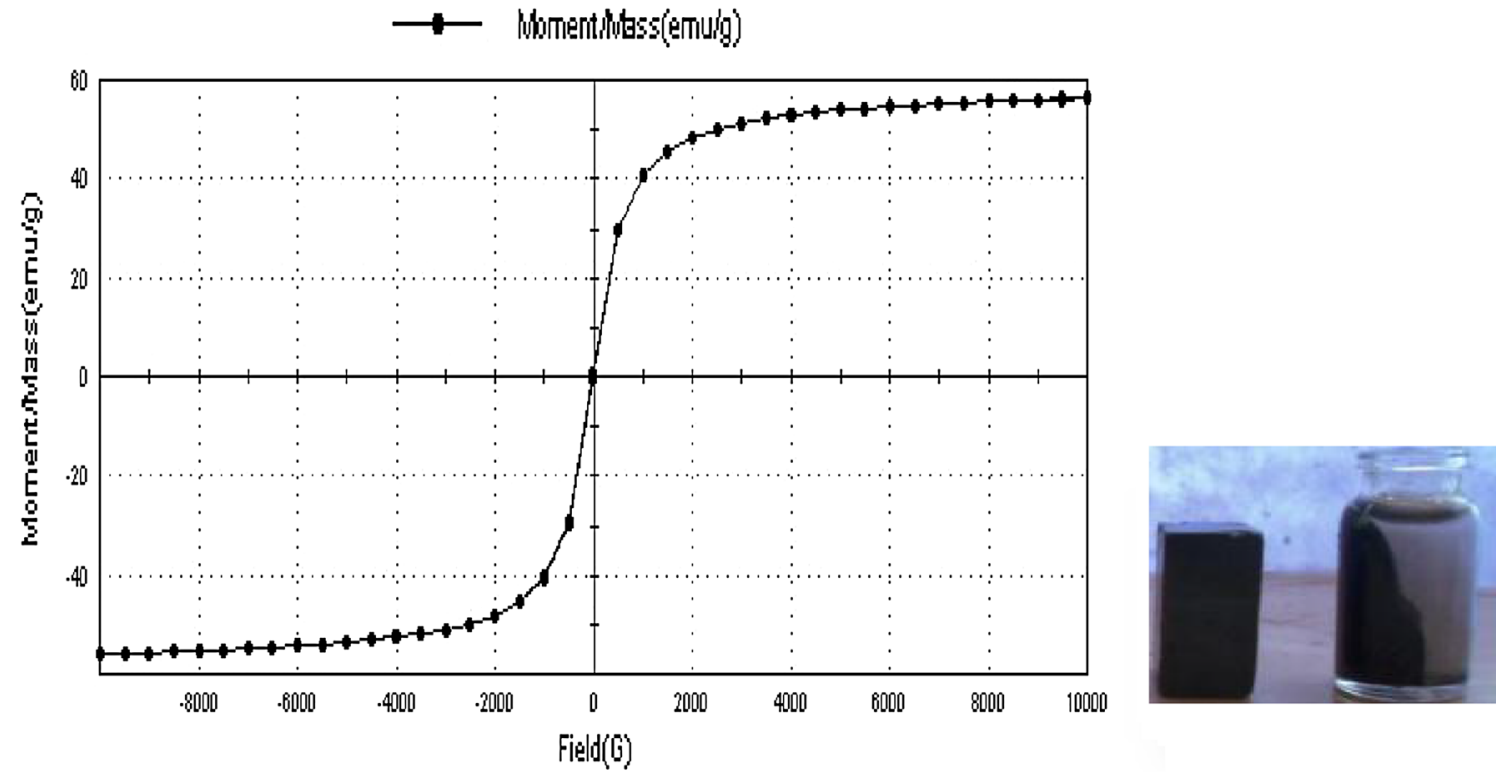

Fig. 10 VSM hysteresis loop of magnetic nanoadsorbent

$q_{\mathrm{t}}=q_{\mathrm{e}}-q_{\mathrm{e}} \exp \left(-K_{1} t\right)$

where $q_{\mathrm{t}}$ and $q_{\mathrm{e}}$ are the amounts of metal adsorbed at time $t$ and equilibrium, respectively, and $K_{1}\left(\mathrm{~min}^{-1}\right)$ is the firstorder reaction rate constant. The pseudo-second-order kinetic model considered in this study is given as (Chen et al. 2008; Basha and Murthy 2007) Eq. (3).

$t / q_{\mathrm{t}}=1 / \mathrm{K}_{2} q_{\mathrm{e} 2}+t / q_{\mathrm{e}}$ where $K_{2}\left(\mathrm{gmg}^{-1} \mathrm{~min}^{-1}\right)$ is the second-order reaction rate constant. The experimental data and the parameters of both models are tabulated in Table 2. It is obvious that the coefficient of correlation $\left(R^{2}=0.99\right)$ for the pseudo-second-order kinetic model is higher in comparison with the pseudo-first-order kinetic model $\left(R^{2}=0.97\right)$ for $\mathrm{Zn}(\mathrm{II})$ ion adsorption. The calculated value of $q_{\mathrm{e}}$ for the pseudo-second-order kinetic model is very close to the experimental 
Table 2 The comparison between adsorption rate constants, the estimated $\mathrm{q}_{\mathrm{e}}$ and the coefficients of correlation associated with the Lagergren pseudo-first-order and the pseudo-second-order kinetic models at $25{ }^{\circ} \mathrm{C}$

\begin{tabular}{|c|c|c|c|c|c|c|}
\hline \multirow[t]{2}{*}{ Adsorbent dose $\left(\mathrm{g} \mathrm{L}^{-1}\right)$} & \multirow{2}{*}{$\begin{array}{l}\text { Initial metal } \\
\text { concentration in }\left(\mathrm{mg} \mathrm{L}^{-1}\right)\end{array}$} & \multirow[t]{2}{*}{ Adsorbent } & \multicolumn{4}{|c|}{ First-order kinetics } \\
\hline & & & $q_{\mathrm{e}}(\exp )$ & $K_{1}$ & $q_{\mathrm{e}}(\mathrm{cal})$ & $R^{2}$ \\
\hline 1 & 10 & \multirow{6}{*}{$\begin{array}{l}\text { Magnetic } \\
\text { nanoadsorbent }\end{array}$} & 3.7 & 0.02 & 4.5 & 0.97 \\
\hline 2 & 30 & & 3.3 & 0.03 & 4.8 & 0.96 \\
\hline \multirow{2}{*}{$\begin{array}{l}\text { Adsorbent } \\
\text { dose }\left(\mathrm{g} \mathrm{L}^{-1}\right)\end{array}$} & \multirow{2}{*}{$\begin{array}{l}\text { Initial metal } \\
\text { concentration in }\left(\mathrm{mg} \mathrm{L}^{-1}\right)\end{array}$} & & \multicolumn{4}{|c|}{ Pseudo-second-order } \\
\hline & & & $q_{\mathrm{e}}(\exp )$ & $K_{2}$ & $q_{\mathrm{e}}(\mathrm{cal})$ & $R^{2}$ \\
\hline 1 & 10 & & 3.7 & 0.76 & 3.5 & 0.99 \\
\hline 2 & 30 & & 3.8 & 0.73 & 3.62 & 0.99 \\
\hline
\end{tabular}

Table 3 Thermodynamic parameters for adsorption of $\mathrm{Zn}$ (II) from aqueous solution by magnetic nanoadsorbent

\begin{tabular}{llll}
\hline $\begin{array}{l}\text { Temperature } \\
(\mathrm{K})\end{array}$ & $\begin{array}{l}\Delta G^{\circ} \\
\left.(\mathrm{kcal} \mathrm{mol})^{-1}\right)\end{array}$ & $\begin{array}{l}\Delta H^{\circ} \\
\left(\mathrm{kcal} \mathrm{mol}^{-1}\right)\end{array}$ & $\begin{array}{l}\Delta S^{\circ} \\
\left(\mathrm{kcal} \mathrm{mol}^{-1}\right)\end{array}$ \\
\hline 303 & 7.23 & 33.42 & 0.5696 \\
313 & 8.12 & & \\
323 & 10.21 & & \\
\hline
\end{tabular}

value. Similar experimental results indicate that the pseudo-second-order kinetic model fits the equilibrium data for heavy metal ion sorption on biomasses from aqueous solutions quite well (Chen et al. 2008; Sari and Tuzen 2008; Sari and Tuzen 2010). The comparison between adsorption rate constants, the estimated $\mathrm{q}_{\mathrm{e}}$ and the coefficients of correlation associated with the Lagergren pseudo-first-order and the pseudo-second-order kinetic models at $25{ }^{\circ} \mathrm{C}$.

\section{Thermodynamic studies}

Thermodynamic studies are used to decipher any reaction in a better way. In the present studies also, thermodynamic studies were performed and the parameters, namely free energy change $\left(\Delta G^{\circ}\right)$, enthalpy $\left(\Delta H^{\circ}\right)$, and entropy $\left(\Delta S^{\circ}\right)$, were determined at 303,313 and $323 \mathrm{~K}$, respectively (shown in Table 3). Thermodynamic parameters were calculated using the following four equations Eq. (4)-(7).

$K_{\mathrm{c}}=C_{\mathrm{ac}} / C_{\mathrm{e}}$

$\Delta G_{\mathrm{o}}=-\mathrm{RT} \ln K_{\mathrm{c}}$

$\Delta H^{\circ}=\mathrm{RT}_{2} T_{1} / T_{2}-T_{1} \ln K_{2} / K_{1}$

$\Delta S^{\circ}=\Delta H^{\circ}-\Delta G^{\circ} / T$

$K_{\mathrm{c}}$ is the equilibrium constant, and $C_{\mathrm{ac}}$ and $C_{\mathrm{e}}$ are the equilibrium concentration of metal ions on the adsorbent ( $\mathrm{m} \mathrm{L} \mathrm{L}^{-1}$ ) and the equilibrium concentration of the metal ions in the solution $\left(\mathrm{mg} \mathrm{L}^{-1}\right)$, respectively. The values of $K_{\mathrm{c}}$ increased as the temperature is increased, indicating the endothermic nature of the process of removal. The values of these parameters are given in Table 2. Positive value of entropy change $\Delta S^{\circ}$ and enthalpy change $\Delta H^{\circ}$ also indicate the endothermic nature of adsorption of $\mathrm{Zn}$ (II) in magnetic nanoadsorbent. It is noted that values of $\Delta G^{\circ}$ decrease with increasing temperature.

\section{Conclusion}

- The employed magnetic nanoadsorbent for $\mathrm{Zn}$ (II) ions removal was influenced by various parameters such as Initial $\mathrm{pH}$, Initial $\mathrm{Zn}(\mathrm{II})$ ions concentration, contact time and adsorbent dose. The maximum adsorption $\mathrm{Zn}$ (II) ions on magnetic $\mathrm{Fe}_{3} \mathrm{O}_{4}$ nanoparticles occurred at $\mathrm{pH}$ 5.5.

- The SEM analysis study of magnetic nanoadsorbent before and after treatment shows distinct removal of $\mathrm{Zn}$ (II) ions and adsorbent shows nanosized particles. Also, EDX study indicates the Zn(II) ions were clearly adsorbed from EDX analysis data.

- The XRD result shows the different $2 \theta$ peaks, which show different planes and sizes of $\mathrm{Fe}_{3} \mathrm{O}_{4}$ nanoparticles calculated by Scherrer formula.

- The VSM analysis of $\mathrm{Fe}_{3} \mathrm{O}_{4}$ nanoparticles shows sufficient magnetic properties.

- Equilibrium and thermodynamic study of $\mathrm{Zn}(\mathrm{II})$ ion removal shows that the adsorption process is spontaneous and endothermic.

Acknowledgments Authors gratefully acknowledge Shri.G.H. Raisoni Doctoral Fellowship at North Maharashtra University, Jalgaon for Financial Support and North Maharashtra University, Jalgaon for SEM, EDX and XRD studies and thankful to Dept. of Physics, Pune University for VSM characterization. Authors are also thankful to the Principal G.T.P. College, Nandurbar for providing necessary laboratory facilities and FTIR characterization.

Open Access This article is distributed under the terms of the Creative Commons Attribution License which permits any use, distribution, and reproduction in any medium, provided the original author(s) and the source are credited. 


\section{References}

Alyuz B, Veli S (2009) Kinetics and equilibrium studies for the removal of nickel and zinc from aqueous solutions by ion exchange resins. J Hazard Mater 167:482-488

Basha S, Murthy ZVP (2007) Kinetic and equilibrium models for biosorption of $\mathrm{Cr}(\mathrm{VI})$ on chemically modified seaweed, Cystoseira indica. Process Biochem 42:1521-1529

Bergbäck B (1992) Industrial metabolism. The emerging landscape of heavy metal immission in Sweden. Dissertion, Linköping studies in Arts and Science, $\mathrm{p} 76$

Campbell PGC, Stokes PB and Galloway JH (1983) Effects on atmospheric deposition on the geochemical cycling and biological availability of metals. In: Proceedings of heavy metals in the environment, International Conference, Heidelberg, CEPConsultants, Edinburgh vol 2, pp 760-763

Chen Z, Ma W, Han M (2008) Biosorption of nickel and copper onto treated alga (Undaria pinnatifida): application of isotherm and kinetic models. J Hazard Mater 155:327-333

Gu HW, Xu KM, Xu CJ, Xu B (2006) Biofunctional magnetic nanoparticles for protein separation and pathogen detection. Chem Commun 6:941-949

Kang YS, Risbud S, Rabolt JF, Stroeve P (1996) Synthesis and characterization of nanometer-size $\mathrm{Fe}_{3} \mathrm{O}_{4}$ and $\mathrm{Fe}_{2} \mathrm{O}_{3}$ particles. Chem Mater 8:2209-2212

Katz E, Willner I (2003) Magnetic control of electrocatalytic and bioelectrocatalytic processes. Angew Chem Int Ed 42:45764588

Kim DH, Lee SH, Im KH, Kim KN, Kim KM, Shim IB, Lee MH, Lee YK (2006) Surface-modified magnetite nanoparticles for hyperthermia: reparation, characterization, and cytotoxicity studies, Curr Appl Phys 6(S1):e242-e246

Ma M, Zhang Y, Yu W, Shen HY, Zhang HQ, Gu N (2003) Colloids Surf. Physicochem Eng Asp 212:219-226

Mikhaylova M, Kim DK, Bobrysheva N, Osmolowsky M, Semenov V, Tsakalakos T, Muhammed M (2004) Superparamagnetism of magnetite nanoparticles: dependence on surface modification. Langmuir 20:2472-2477

Nasuha N, Hameed BH, Mohd Din AT (2010) Rejected tea as a potential low-cost adsorbent for the removal of methylene blue. J Hazard Mater 175:126-132
Ngomsik A, Bee A, Draye M, Cote G, Cabuil V (2005) Magnetic nano and microparticles for metal removal and environmental applications: a review. C R Chimie 8:963-970

Riaz M, Nadeem R, Hanif MA, Ansari TM, Rehman KU (2009) $\mathrm{Pb}$ (II) biosorption from hazardous aqueous streams using Gossypium hirsutum (Cotton) waste biomass. J Hazard Mater 161:88-94

Ross S (1994) Sources and forms of potentially toxic metals in soilplant systems. In: Ross S (ed) Toxic metals in soil-plant systems, Wiley, Chichester, pp 23-25

Santra S, Tapec R, Theodoropoulou N, Dobson J, Hebard A, Tan WH (2001) Synthesis and characterization of silica-coated iron oxide nanoparticles in microemulsion: the effect of nonionic surfactants. Langmuir 17:2900-2906

Sari A, Tuzen M (2008a) Biosorption of $\mathrm{Pb}(\mathrm{II})$ and $\mathrm{Cd}(\mathrm{II})$ from aqueous solution using green alga (Ulva lactuca) biomass. J Hazard Mater 152:302-308

Sari A, Tuzen M (2008b) Biosorption of total chromium from aqueous solution by red algae (Ceramium virgatum): equilibrium, kinetic and thermodynamic studies. J Hazard Mater 160:349-355

Sari A, Tuzen M (2010) Biosorption of selenium from aqueous solution by green algae (Cladophora hutchinsiae) biomass: equilibrium, thermodynamic and kineticstudies. Chem Eng J 158:200-206

Siegel RW, Hu E, Roco MC (1999) Nanostructure science and technology: a worldwide study. WTEC, Loyola College Kluwer Academic, Baltimore

Suslick KS, Fang M, Hyeon T (1996) Sonochemical synthesis of iron colloids. J Am Chem Soc 118:11960-11961

Wa SR, Huang JS, Yan HS (2006) Size-controlled preparation of magnetitenanoparticles in the presence of graft copolymers. J Mater Chem 16:298-303

Waldron RD (1995) Phys Rev 99:1727-1735

Woo K, Hong J, Choi S, Lee H, Ahn J, Kim CS, Lee SW, (2004) Easy synthesis and magnetic properties of iron oxide nanoparticles, Chem. Mater: 162814-3218

Zhao Y, Qui Z, Huang J (2008) Preparattion and analysis of $\mathrm{Fe}_{2} \mathrm{O}_{3}$ magnetic nanoparticles used as targeted-drug. Carr Chinese $\mathrm{J}$ chem Eng 16(3):451-455 